\title{
Effect of magnesium modification over H-ZSM-5 in methanol to propylene reaction
}

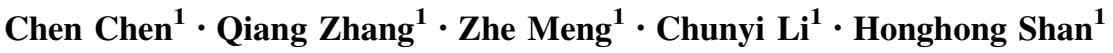

Received: 31 May 2015/Accepted: 21 July 2015/Published online: 13 August 2015

(c) The Author(s) 2015. This article is published with open access at Springerlink.com

\begin{abstract}
H-ZSM-5-based catalyst is a recognized catalyst which is particularly selective towards the formations of light olefins in the methanol reaction. A series of H-ZSM-5 $\left(\mathrm{SiO}_{2} / \mathrm{Al}_{2} \mathrm{O}_{3}=38\right)$ modified with different amounts of magnesium have been investigated. All the samples were characterized by $\mathrm{X}$-ray diffraction instrument (XRD), temperature-programmed desorption of $\mathrm{NH}_{3}\left(\mathrm{NH}_{3}-\right.$ TPD) and Fourier Transform Infrared Spectoscopy (FTIR). The results indicated that the impregnation of H-ZSM$5\left(\mathrm{SiO}_{2} / \mathrm{Al}_{2} \mathrm{O}_{3}=38\right)$ zeolite with various magnesium loading amount significantly affected the strength of acid sites and decreased the concentration of both weak and strong acid sites. As a result of modification, magnesium mainly interacted with strong Brønsted acid sites, thus generated new medium strong acid sites and enhanced the yield of propylene. The optimum acid property for methanol to propylene (MTP) reaction was gotten over 4.0 Mg-ZSM-5 (4.0 wt\% Mg) zeolite catalyst. The maximum yield of propylene was $10.62 \mathrm{wt} \%$ over $4.0 \mathrm{Mg}$ ZSM-5 zeolite catalyst by the $30 \mathrm{~min}$ on stream. Coke which was mostly formed on strong Brønsted acid sites, would cause the catalysts deactivation, so the reduction of strong Brønsted acid sites could enhance the catalytic stability.
\end{abstract}

Keywords ZSM-5 $\cdot$ Mg $\cdot$ Modification $\cdot$ Acidity · Deactivation

Qiang Zhang

girlzhangqiang@163.com

$\triangle$ Chunyi Li

chyli@upc.edu.cn

1 State Key Laboratory of Heavy Oil Processing, China University of Petroleum, Qingdao 266580, China

\section{Introduction}

Propylene is one of the most important organic raw materials for the synthesis of a variety of important downstream chemical materials, such as polypropylene, acrylonitrile, epoxy propane, etc. From the data ranged from 2005 to 2013, the apparent consumption of raw petroleum increased year by year, the world's industrial production depended heavily on fossil fuels for energy, such as coal, petroleum and natural gas. Due to the increasing price of crude oil and the demand for light olefins, as well as the larger demand for propylene than ethylene, a growing number of researchers were dedicating to developing the non-oil route for producing low carbon olefins, in especial, propylene [1-8]. The development of methanol-to-olefins (MTO) process can effectively reduce the dependence on oil resources in the propylene industrial $[1,4,5]$.

In recent years, synthetic erionite, offretite, mordenite, SAPO-34 and ZSM-n were applied in MTO process [3-7]. On the basis of previous research findings in the past few years, SAPO-34 and ZSM-5 zeolites standed out from zeolite molecular sieves and non-zeolite molecular sieves [4, 6-9]. Among a variety of materials, H-ZSM-5 shows excellent performance in MTO process. H-ZSM-5 zeolite has the following three advantages: (I) good thermal and hydrothermal stability; (II) slow carbon deactivation rate; (III) mature synthetic process and lower cost [5].

Many efforts have been made to improve light olefins selectivity and lifetime of the catalysts by modification of H-ZSM-5 catalyst. The acidity of catalyst plays an important role in catalytic activity through MTO reaction, and acid adjustment is the most significant affecting factor for product distribution and catalytic stability [10-18]. Many methods could adjust the catalysts acid properties for a better catalytic performance. For example, metal hetero- 
atoms were applied at the stage of gel formation to replace $\mathrm{Al}$ in zeolite framework, which result in higher selectivity of light olefins [14]. It was also reported previously that transition metal cations $\left(\mathrm{Ga}^{3+}, \mathrm{Zn}^{2+}\right)$ exhibited Lewis acid properties over zeolite [17, 18]. After the impregnation of element $\mathrm{Ga}$, zeolite acid sites appeared to be weaker than parent zeolite, and only weak acid sites existed [17]. Zn containing H-ZSM-5 zeolite catalyst showed a remarkable change in acidity properties, the number of strong acid sites decreased due to the impregnation of $\mathrm{Zn}^{2+}$ [18]. Abramova reported that the impregnation of magnesium decreased the amount of total acid sites and strong acid sites, as a result, enhanced the catalytic stability [19].

After years of investigation, researchers have achieved good results in the application of H-ZSM-5 zeolite in MTO reaction. Much more deep explorations are still need to take in, such as, the mechanism of propylene production on acid sites, the optimum acid properties in methanol to propylene (MTP) reaction, and the most appropriate modified element. Further improving the catalytic performance, both catalytic stability and selectivity of main product, these are the challenges researchers recently face.

In this work, zeolite H-ZSM-5 $\left(\mathrm{SiO}_{2} / \mathrm{Al}_{2} \mathrm{O}_{3}=38\right)$ was synthesized based on the stepwise hydrothermal synthesis method. Modified zeolites were prepared by H-ZSM-5 $\left(\mathrm{SiO}_{2} / \mathrm{Al}_{2} \mathrm{O}_{3}=38\right)$ and magnesium nitrate hexahydrate with different magnesium loading content. The main purposes are to get the optimum acidity, the highest selectivity of propylene and the prolonged high methanol conversion.

\section{Experimental}

\section{Catalyst preparation}

H-ZSM-5 zeolite samples with $\mathrm{SiO}_{2} / \mathrm{Al}_{2} \mathrm{O}_{3}=38$ were synthesized based on the stepwise hydrothermal synthesis assembled method from a gel mixture. In the gel mixture, sodium silicate and aluminum sulfate were used as the starting materials for $\mathrm{Si}$ and $\mathrm{Al}$ components, respectively. $\mathrm{N}$-Butylamine was used as organic template. When crystallization was completed, Na-ZSM-5 was gotten. NaZSM-5 was washed by water until the $\mathrm{pH}$ of filter liquor value came to 7 . Then Na-ZSM-5 was calcinated in muffle furnace at $550{ }^{\circ} \mathrm{C}$ for $3 \mathrm{~h}$ to remove template. Finally ammonium ion exchange process was taken to change $\mathrm{Na}$ ZSM-5 into $\mathrm{NH}_{4}$-ZSM-5. H-ZSM-5 was gotten after samples being calcinated at $550{ }^{\circ} \mathrm{C}$ for $3 \mathrm{~h}$ in a muffle furnace $\left(5^{\circ} \mathrm{C} / \mathrm{min}\right)$.

After the synthesis of H-ZSM-5 samples, nMg-ZSM$5(n=1.0,2.0,4.0,6.0,8.0)$ with different loading amounts of magnesium were prepared by H-ZSM-5 $\left(\mathrm{SiO}_{2} /\right.$ $\mathrm{Al}_{2} \mathrm{O}_{3}=38$ ) zeolite and magnesium nitrate hexahydrate
$\left(\mathrm{Mg}\left(\mathrm{NO}_{3}\right)_{2} \cdot 6 \mathrm{H}_{2} \mathrm{O}\right)$. Impregnation was chosen as the modification procedure. The weight of the magnesium nitrate hexahydrate $\left(\mathrm{Mg}\left(\mathrm{NO}_{3}\right)_{2} \cdot 6 \mathrm{H}_{2} \mathrm{O}\right)$ was based on the mass fraction of $\mathrm{MgO}$ to $\mathrm{H}-\mathrm{ZSM}-5$ zeolite. The concentration of dipping solution was about $0.25 \mathrm{~mol} / \mathrm{L}$. Every sample was dipped three times. After impregnation, modified samples were drying out under $140{ }^{\circ} \mathrm{C}$ over night and calcinated at $550{ }^{\circ} \mathrm{C}$ for $2 \mathrm{~h}$ in air $\left(10^{\circ} \mathrm{C} / \mathrm{min}\right)$.

\section{Catalyst characterization}

The crystal structure of the samples were inspected by an X'Pert PRO MPD diffractometer system using $\mathrm{Cu} \mathrm{Ka}$ radiation at $40 \mathrm{kV}$ and $40 \mathrm{~mA}$, running from $3.431^{\circ}$ to $61.051^{\circ}$ with a speed of $10 \% \mathrm{~min}$.

The catalyst acidic properties were measured by temperature-programmed desorption of $\mathrm{NH}_{3}\left(\mathrm{NH}_{3}\right.$-TPD) and Fourier Transform Infrared Spectoscopy (FT-IR). Catalyst acidic properties include acid amount, type of the acid sites, and acid strength. $\mathrm{NH}_{3}$-TPD was applied to calculate the amount and measure the strength of acid sites. In a typical analysis, about $0.100 \mathrm{~g}$ modified catalyst was pretreated in a flow of $\mathrm{He}(30 \mathrm{~mL} / \mathrm{min})$ while heating from room temperature to $650{ }^{\circ} \mathrm{C}\left(10^{\circ} \mathrm{C} / \mathrm{min}\right)$ and keep $650{ }^{\circ} \mathrm{C}$ for $30 \mathrm{~min}$. And then the sample was treated in a flow of ammonia gas for $30 \mathrm{~min}$. After purging with $\mathrm{He}(30 \mathrm{~mL} /$ $\min$ ) for $2 \mathrm{~h}$, the measurement was carried out from 100 to $650{ }^{\circ} \mathrm{C}$ at a heating rate of $10{ }^{\circ} \mathrm{C} / \mathrm{min}$.

The type of the acid sites was measured by FT-IR spectra of pyridine adsorption with a Mercury Cadmm Telluride (MCT) detector using a Nexsus ${ }^{\text {TM }}$ FT-IR spectrometer. The spectra were recorded with $4 \mathrm{~cm}^{-1}$ and 64 scans.

\section{Catalyst performance test}

MTP experiments were carried out in a fix-bed reactor at $450{ }^{\circ} \mathrm{C}$, the experiment pressure was atmospheric pressure. The catalyst sample weighting $1.0 \mathrm{~g}$, was loaded in the center of the stainless steel reactor (I.D. $=16 \mathrm{~mm}$ and length $=180 \mathrm{~mm})$. The catalyst was heated in a flow of $\mathrm{N}_{2}$ (40 $\mathrm{mL} / \mathrm{min}$ ) while heating from ambient temperature to $450{ }^{\circ} \mathrm{C}$. After removing the physically absorbed water from catalyst surface, a feed of pure methanol with the weight hourly space velocity (WHSV) of $9.78 \mathrm{~h}^{-1}$ was pumped into the reactor. The gaseous products of the MTP reaction were confirmed by a Bruker 450 gas chromatograph equipped with a flame ionization detector (FID) to determine the hydrocarbons and two thermal conductivity detector (TCD) to analyze the amount of carbon dioxide, carbon monoxide, and hydrogen. Unreacted methanol in liquid was analyzed by an Agilent 6820 gas chromatograph using ethanol as external standard. 
Correction factor for methanol, methanol conversion, and product yield were calculated as follows:

Correction factor for methanol

$\mathrm{F}_{\text {methanol }}=\frac{m_{\text {methanol }} \times S_{\text {ethanol }}}{S_{\text {methanol }} \times m_{\text {ethanol }}}$

Methanol conversion

Conversion $_{\text {methanol }}=\frac{\text { methanol }_{\text {in }}-\text { methanol }_{\text {out }}}{\text { methanol }_{\text {in }}} \times 100 \mathrm{wt} \%$

Yield of light olefins

Yield $_{\text {lightolefin }}=\frac{m_{i}}{\text { methanol }_{\text {in }}-\text { methanol }_{\text {out }}} \times 100 \mathrm{wt} \%$

Product selectivity in light olefins

Selectivity $_{\text {lightolefin }}=\frac{\text { Yield }_{i}}{\text { Yield }_{\text {allightolefins }}} \times 100 \%$

Weight hourly space velocity

$\mathrm{WHSV}=\frac{m_{\text {methanol }}}{m_{\text {catalyst }}} h^{-1}$

\section{Results and discussion}

\section{Structure properties}

X-ray diffraction (XRD) patterns of magnesium modified ZSM-5 $\left(\mathrm{SiO}_{2} / \mathrm{Al}_{2} \mathrm{O}_{3}=38\right)$ samples are shown in Fig. 1. It revealed that the modified samples still maintained the

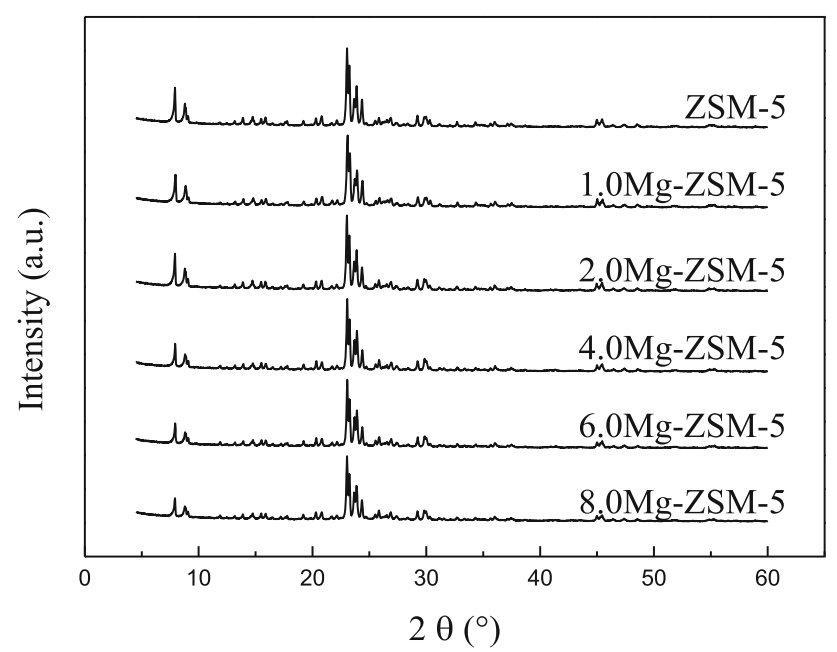

Fig. 1 X-ray powder diffraction patterns of modified samples with various $\mathrm{Mg}$ loading mobil five (MFI) structure. Parent H-ZSM-5 $\left(\mathrm{SiO}_{2} /\right.$ $\mathrm{Al}_{2} \mathrm{O}_{3}=38$ ) zeolite was regarded as the base sample to determine the relative crystallinity of the modified zeolites. The relative crystallinity of modified sample was calculated and presented in Table 1.

In previous reports, impregnation might cause the framework dealumination, finally resulted in the reduction of crystallinity of zeolite [20,21]. The XRD results exhibited that the parent H-ZSM-5 and magnesium modified H-ZSM-5 samples consisted exclusively of the diffraction peaks for intrinsic MFI structure. No extra peak related to $\mathrm{MgO}$ exhibited in the XRD patterns, which revealed uniform dispersion of modifier.

The relative crystallinity of $1.0 \mathrm{Mg}-\mathrm{ZSM}-5,2.0 \mathrm{Mg}$ ZSM-5, 4.0 Mg-ZSM-5, 6.0 Mg-ZSM-5, 8.0 Mg-ZSM-5 was calculated to be $97.10,89.25,88.25,83.47,76.98 \%$, respectively. It revealed that, though modified zeolites showed typical XRD pattern for MFI structure, the structures were destroyed as a result of the incorporation with $\mathrm{Mg}$. The more $\mathrm{Mg}$ was incorporated, the lower relative crystallinity would be gotten.

\section{Catalytic performance}

In order to explore the role of acid character in MTP reaction and to enhance propylene selectivity, we imported $\mathrm{Mg}$ onto H-ZSM-5 $\left(\mathrm{SiO}_{2} / \mathrm{Al}_{2} \mathrm{O}_{3}=38\right)$ to adjust the acid property and find optimum acidity for MTP reaction. Experiments were carried out at $450{ }^{\circ} \mathrm{C}$ with a pure methanol feed WHSV of $9.78 \mathrm{~h}^{-1}$ under atmospheric pressure. The catalyst loading amount was $1.0 \mathrm{~g}$. Figure 2 shows the conversion profiles of methanol over Mg modified H-ZSM-5 zeolites under the same reaction condition, with reaction time on stream (TOS).

As the conversion profiles showed in Fig. 2, high conversion of methanol over modified zeolites was detected at the beginning of reaction, which was due to perfect crystal structure. Methanol totally reacted over parent H-ZSM-5 zeolite catalyst, but the conversion of methanol decreased to $98.37 \mathrm{wt} \%$ when $\mathrm{Mg}$ loading amount was $8.0 \mathrm{wt} \%$. The structural integrity of catalyst also affects the activity of catalysts [22]. Based on the relative crystallinity of modified zeolites shown in Table 1, we preliminarily assumed that the decrease of catalyst activity could be attributed to the destruction of crystal structure caused by modification.

It also revealed that catalytic stability was enhanced with the impregnation of Mg. It is clearly shown in Fig. 2,

Table 1 Relative crystallinity of modified zeolites with different amount of $\mathrm{Mg}$

\begin{tabular}{llllll}
\hline Zeolite sample & $1.0 \mathrm{Mg}-\mathrm{ZSM}-5$ & $2.0 \mathrm{Mg}-\mathrm{ZSM}-5$ & $4.0 \mathrm{Mg}-\mathrm{ZSM}-5$ & $6.0 \mathrm{Mg}-\mathrm{ZSM}-5$ & $8.0 \mathrm{Mg}-\mathrm{ZSM}-5$ \\
\hline Relative crystallinity $(\%)$ & 97.10 & 89.25 & 88.25 & 83.47 & 76.98 \\
\hline
\end{tabular}


the rate of deactivation decreased with the increase of $\mathrm{Mg}$ loading. In the first $60 \mathrm{~min}$, the deactivation rate of 8.0 Mg-ZSM-5 was the slowest among modified samples. After $60 \mathrm{~min}$, the deactivation rate of $8.0 \mathrm{Mg}$-ZSM-5 increased, at the same time, 4.0 Mg-ZSM-5 remained relatively slow inactivation rate. At $120 \mathrm{~min}$ of TOS, the conversion rate of methanol over $4.0 \mathrm{Mg}-\mathrm{ZSM}-5$ was greater than $90 \mathrm{wt} \%$. As a whole, the deactivation rate was slowed down due to the impregnation of magnesium.

In addition to the obvious change of catalyst activity, the distribution of products changed after modification. Experiment data for both parent H-ZSM-5 and Mg modified H-ZSM-5 samples are listed in Table 2. As shown in Table 2, it could be noticed that, the yield of light olefins was enhanced with the impregnation of magnesium. When Mg loading was $4.0 \mathrm{wt} \%$, the yield of propylene increased from 3.87 to $8.83 \mathrm{wt} \%$, besides, the yield of butylene increased from 1.11 to $3.52 \mathrm{wt} \%$. Along with the following increase of $\mathrm{Mg}$ loading, the yield of propylene declined slightly. But when the $\mathrm{Mg}$ loading reached $8.0 \mathrm{wt} \%$, the

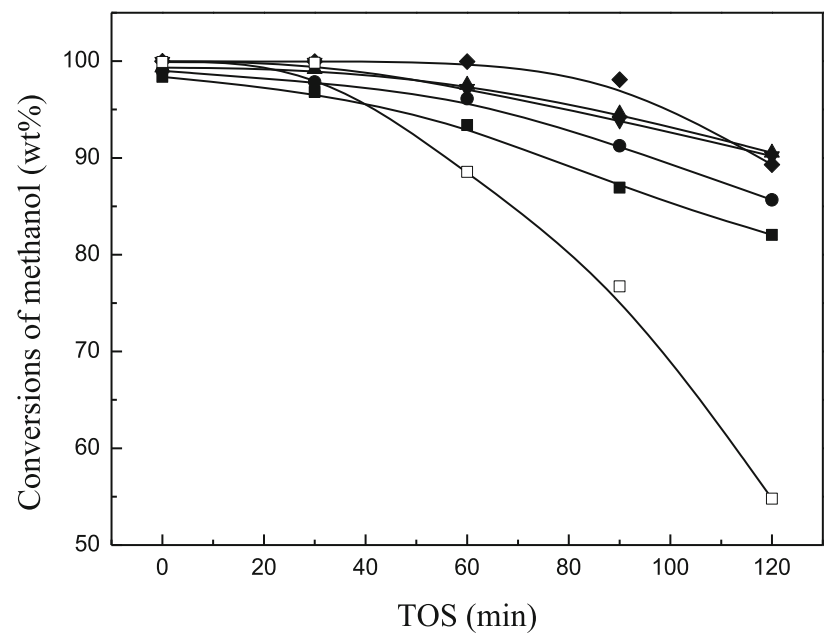

Fig. 2 Conversion of methanol over modified H-ZSM-5 zeolite catalysts (open square parent $\mathrm{H}-\mathrm{ZSM}-5$, open rectangle $1.0 \mathrm{Mg}-$ ZSM-5, inverted filled triangle $2.0 \mathrm{Mg}-\mathrm{ZSM}-5$, filled triangle $4.0 \mathrm{Mg}-$ ZSM-5, filled circle 6.0 Mg-ZSM-5, filled square $8.0 \mathrm{Mg}-\mathrm{ZSM}-5$ ) yield of propylene dropped from 8.83 (4.0 Mg-ZSM-5) to $8.54 \mathrm{wt} \%$, the yield of butylene decreased to $2.92 \mathrm{wt} \%$. The yield of propylene got the steepest increase among the light olefins, followed by butylene.

Then, we got the data of production distribution over modified samples through continuous operation. The selectivity of light olefins and $\mathrm{P} / \mathrm{E}$ ratio at different time over each modified sample are shown in Fig. 3. As shown in Fig. 3, the selectivity of ethylene in light olefins decreased from 41.38 to $25.63 \%$ with $\mathrm{Mg}$ loading increasing from 0.0 (non-modified) to $4.0 \mathrm{wt} \%$. As the experiment progressed, the selectivity of ethylene decreased. In contrast, the selectivity of propylene increased with increasing reaction time. The selectivity of butylene showed the same variation with the selectivity of propylene. The generation of ethylene needed stronger acid sites compared with propylene and butylene. In the initial stage of MTP reaction, a certain amount of acid sites existed on the catalyst surface, so the selectivity of ethylene was higher than propylene and butylene. Coke was formed during the reaction, which might first deposit on the surface with relatively strong acid sites, thus reduced the number of strong acid center. Also, a large amount of strong acid sites belonged to Brønsted acid sites, which were the active centers of hydrogen-transfer reaction. As a result, the selectivity of propylene and butylene increased might due to the decrease of Brønsted acid sites. When the $\mathrm{Mg}$ content increased from 6.0 to $8.0 \mathrm{wt} \%$, the selectivity of ethylene increased, in contrast, the selectivity of propylene and butylene decreased. Excessive amount of Mg might block the pores and channels, which might improve the shape selectivity of zeolite, finally leaded to the increment of ethylene selectivity. As shown in Fig. 3d, $\mathrm{P} / \mathrm{E}$ ratio increased after modification. We got the highest $\mathrm{P} / \mathrm{E}$ ratio over $4.0 \mathrm{Mg}-\mathrm{ZSM}-5$ modified zeolite, and $\mathrm{P} / \mathrm{E}$ ratio decreased as the content of modified promoter increased further. As a result of impregnation of $\mathrm{Mg}$, the yield of light olefins was enhanced, especially for propylene and butylene. It was worth noting that the excessive increase of $\mathrm{Mg}$ load amount could not bring the expected better results. In conclusion, the impregnation of $\mathrm{Mg}$ might

Table 2 Results of MTP reaction over modified H-ZSM-5

\begin{tabular}{|c|c|c|c|c|c|c|c|}
\hline \multirow[t]{2}{*}{ Catalysts } & \multirow[t]{2}{*}{ Conversion (wt\%) } & \multicolumn{6}{|c|}{ Yield (wt\%) } \\
\hline & & $\mathrm{C}_{2} \mathrm{H}_{4}$ & $\mathrm{C}_{3} \mathrm{H}_{6}$ & $\mathrm{C}_{4} \mathrm{H}_{8}$ & $\mathrm{CH}_{4}$ & $\mathrm{C}_{2} \mathrm{H}_{6}$ & $\mathrm{C}_{3} \mathrm{H}_{8}$ \\
\hline ZSM-5 & 100 & 3.53 & 3.87 & 1.11 & 0.99 & 0.57 & 5.27 \\
\hline 1.0 Mg-ZSM-5 & 99.99 & 3.65 & 4.43 & 1.61 & 1.80 & 0.36 & 3.79 \\
\hline 2.0 Mg-ZSM-5 & 99.84 & 4.84 & 7.18 & 2.85 & 0.53 & 0.17 & 2.48 \\
\hline 4.0 Mg-ZSM-5 & 99.35 & 4.26 & 8.83 & 3.52 & 0.40 & 0.07 & 0.80 \\
\hline 6.0 Mg-ZSM-5 & 98.51 & 4.98 & 8.67 & 3.11 & 0.39 & 0.07 & 0.71 \\
\hline $8.0 \mathrm{Mg}-\mathrm{ZSM}-5$ & 98.37 & 5.36 & 8.54 & 2.92 & 0.44 & 0.08 & 0.69 \\
\hline
\end{tabular}



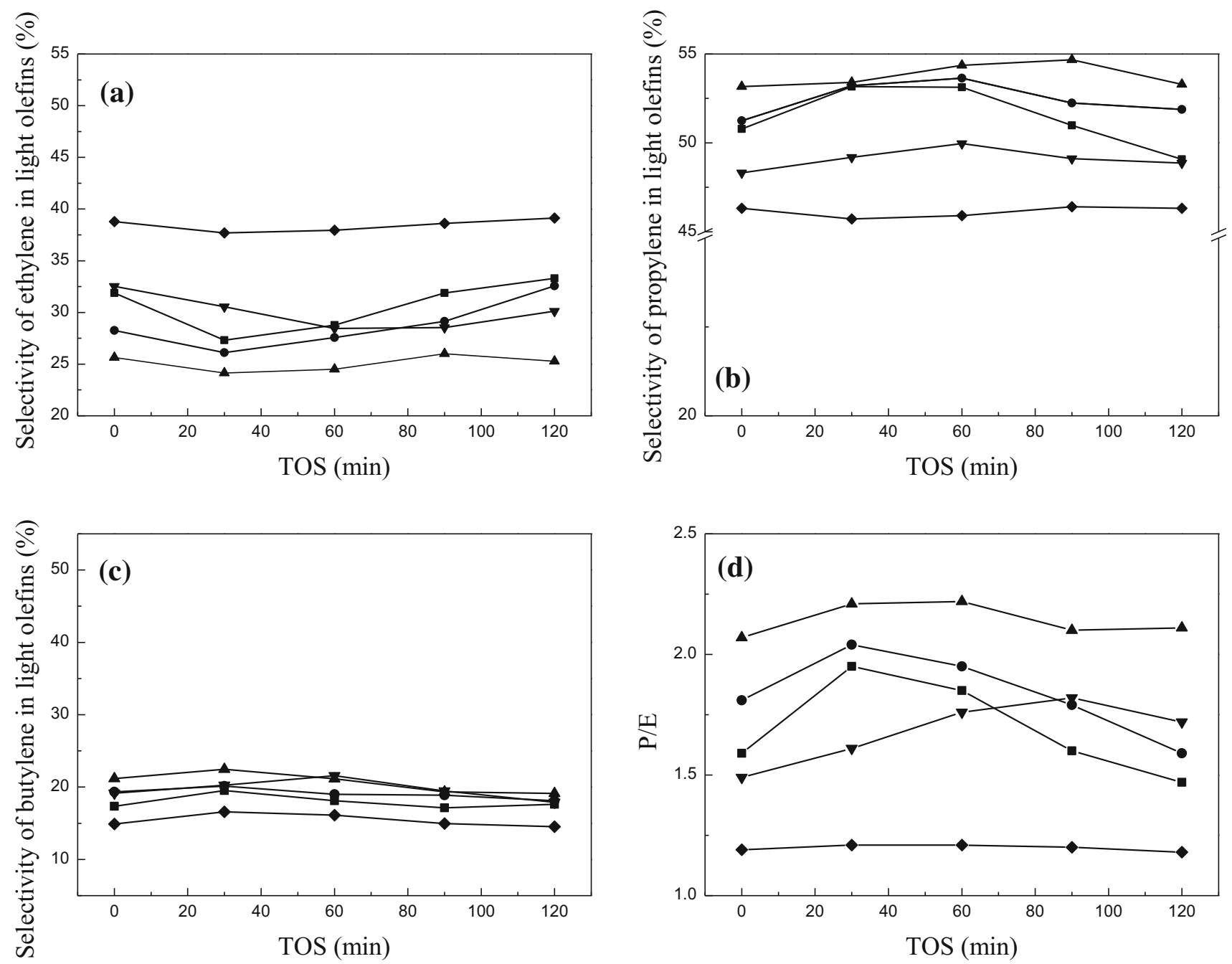

Fig. 3 Yield of light olefins and P/E ratio with TOS over modified H-ZSM-5 catalysts a selectivity of ethylene; b selectivity of propylene; c selectivity of butylene; d Propylene/Ethylene ratio

(open square $1.0 \mathrm{Mg}-\mathrm{ZSM}-5$, inverted filled triangle 2.0 Mg-ZSM-5, filled triangle $4.0 \mathrm{Mg}-\mathrm{ZSM}-5$, filled circle $6.0 \mathrm{Mg}-\mathrm{ZSM}-5$, filled square $8.0 \mathrm{Mg}$-ZSM-5)

change the acid property of these samples, which could also influence the catalyst activity.

\section{Acid property}

The acidity of the magnesium modified H-ZSM-5 zeolite was examined by $\mathrm{NH}_{3}$-TPD and FT-IR.

MTP reaction is an acid catalytic reaction, methanol conversion and production of light olefins are influenced by the characteristic of acid sites [23]. Figure 4 shows that only parent H-ZSM-5 and 1.0 Mg-ZSM-5 zeolite catalysts showed two desorption peaks, which correspond to acid sites of different acid strength. The maximum temperature of desorption peak signifies the strength of acid sites. The first peak had a maximum around $250{ }^{\circ} \mathrm{C}$ corresponding to weak acid sites, the second peak appeared at high temperature was indicative of the presence of strong acid sites.

It was observed, for Mg modified H-ZSM-5 zeolites, the position of two desorption peak switched to a lower temperature compared with parent $\mathrm{H}-\mathrm{ZSM}-5$ zeolite. When $\mathrm{Mg}$ loading amount was more than $4.0 \mathrm{wt} \%$, samples presented only one desorption peak at low temperature. And the position of desorption peak shifted to lower temperature with the increase of $\mathrm{Mg}$ content compared to parent zeolite, which was an indication of weaker acid strength. Compared $\mathrm{NH}_{3}$-TPD plots in Fig. 4 with the conversion profiles in Fig. 2, the result showed that the stronger the acid sites, the faster the deactivation by coke deposition would be caused.

Furthermore, we clearly observed the significant reduction in the area under high temperature peak and increase in area under medium high temperature peak, which indicated the diminishment of the quantity of strong acid sites and the increase of the number of medium strong 


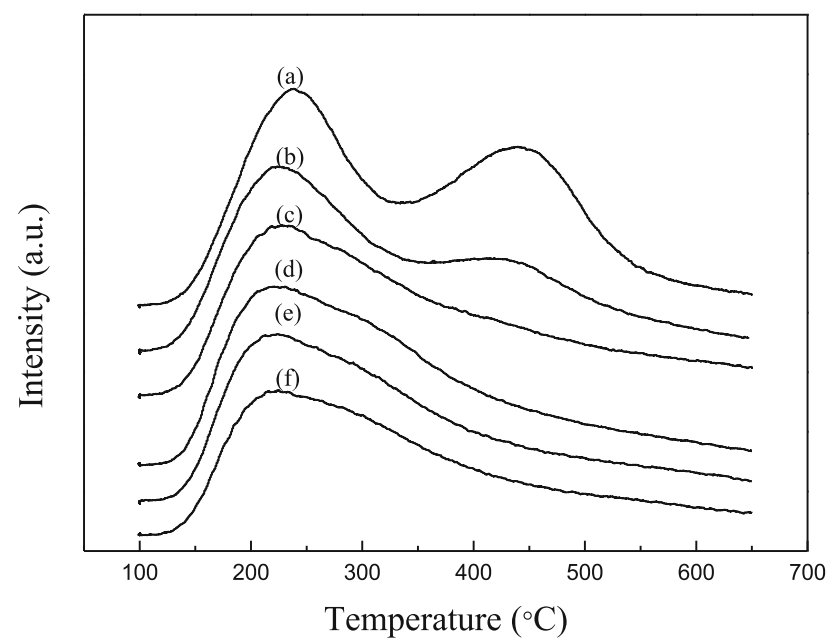

Fig. $4 \mathrm{NH}_{3}$-TPD plots of modified zeolites ( $a$ parent HZSM-5 $\left(\mathrm{SiO}_{2} /\right.$ $\left.\mathrm{Al}_{2} \mathrm{O}_{3}=38\right), b 1.0 \mathrm{Mg}-\mathrm{ZSM}-5, c$ 2.0 Mg-ZSM-5, $d$ 4.0 Mg-ZSM-5, e 6.0 Mg-ZSM-5, f 8.0 Mg-ZSM-5)

acid sites, respectively. It was observed that the modified samples had lower proportion of acid sites, both weak and strong. These changes in acidity due to the interaction of $\mathrm{Mg}$ with zeolite strong acid sites might generate new acid sites [19]. The impregnation of $\mathrm{Mg}$ neutralized surface acid sites and also induced pore plugging, which significantly reduced the quantity and the strength of acid sites [24].

As expected, the total acid content decreased with the increase of Mg loading. From the data showed in Table 3, the amount of weak acid sites decreased slightly. At the same time, strong acid declined dramatically, which resulted in a reduction of inactivation rate. These results could be explained by the interaction of promoter species with parent zeolite framework, which resulted in masking the acid sites and forming new acid sites [25, 26]. The strong acid sites provide the main active sites for methanol dehydration, so it can enhance coke formation and catalyst deactivation. Compared the results in Fig. 2 with the data in Table 3, parent H-ZSM-5 with high concentration of strong acid sites deactivated rapidly, but the modified samples with lower concentration of strong acid sites could maintain their activity for a longer time. Therefore, the

Table 3 Acid properties of modified H-ZSM-5 zeolites

\begin{tabular}{llll}
\hline Catalysts & $\begin{array}{l}\text { Weak acid } \\
\mathrm{mmol} / \mathrm{g}\end{array}$ & $\begin{array}{l}\text { Strong acid } \\
\mathrm{mmol} / \mathrm{g}\end{array}$ & $\begin{array}{l}\text { Total acid } \\
\mathrm{mmol} / \mathrm{g}\end{array}$ \\
\hline ZSM-5 & 0.446 & 0.754 & 1.200 \\
$1.0 \mathrm{Mg}-Z S M-5$ & 0.408 & 0.509 & 0.917 \\
$2.0 \mathrm{Mg}-Z S M-5$ & 0.393 & 0.481 & 0.874 \\
$4.0 \mathrm{Mg}-Z S M-5$ & 0.345 & 0.460 & 0.805 \\
$6.0 \mathrm{Mg}-Z S M-5$ & 0.336 & 0.447 & 0.783 \\
$8.0 \mathrm{Mg}-Z S M-5$ & 0.326 & 0.416 & 0.742 \\
\hline
\end{tabular}

slow deactivation of Mg modified zeolites in the MTP reaction could be explained by the reduction of strong acid sites. In previous studies, two mechanisms were presented, dual cycle mechanism and alkene cycle mechanism. According to the dual cycle mechanism, ethylene and propylene are mainly produced through the cracking of aromatic intermediates, which are generated in the presence of strong acid sites. And propene is additionally produced from the cracking of higher olefin in the alkene cycles [27]. Low number of strong acid sites reduced the amount of active aromatic intermediates, and then lowered the yield of ethylene, but the relatively rapid progress of the alkene cycle might cause a high yield of propene. The declination of ethylene and the increase of propylene in this experiment could be explained by the reduction of strong acid sites, which was necessary for the formation of aromatic intermediates. It was also reported that $[10,28]$, the weak acid sites were active sites for alkylation and methylation reaction, which might result in the increase of olefin production. In addition, relatively weak acidity hindered various side reaction such as hydrogen-transfer reactions, as a result, propylene and butylene yields increased due to fewer hydrogen-transfer reactions.

As shown in Fig. 5, all the samples had two kind of acid sites. The bands at 1546 and $1445 \mathrm{~cm}^{-1}$ were attributed to Brønsted acid site and Lewis acid site, respectively. FT-IR spectra of different modified samples showed certain regular changes. Figure 5 shows that the impregnation of $\mathrm{Mg}$ reduced the amount of Brønsted acid sites and Lewis acid sites. The amount of Brønsted acid sites diminished much more than that of Lewis acid sites. Compared the profiles in Fig. 5 and the data in Table 3, we could presume that the impregnation of $\mathrm{Mg}$ mainly reduced the strong Brønsted acid, which was the main active site aromatic intermediates formed on. In MTP reaction, olefins transferred into

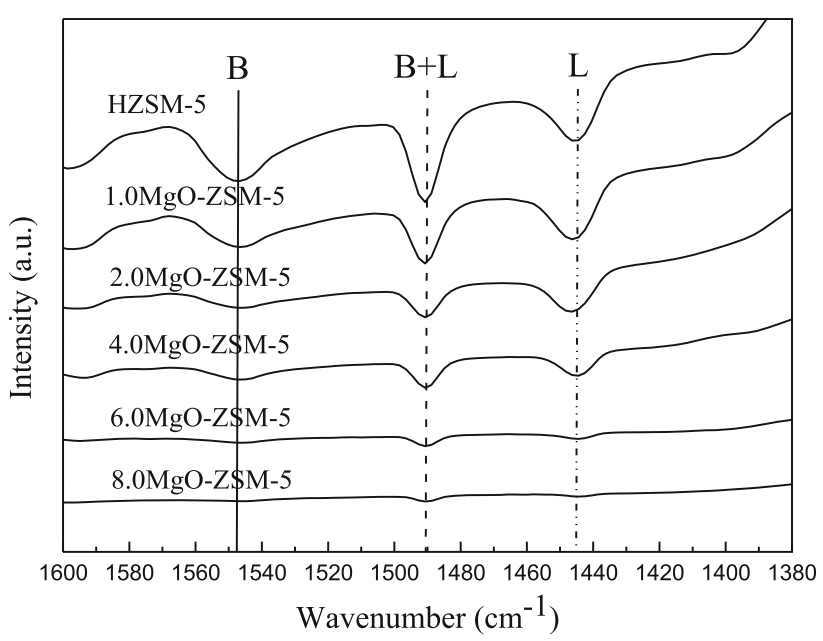

Fig. 5 Py-FTIR spectra of modified H-ZSM-5 zeolite catalysts 
aromatics through polymerization, rearrangement, breakage, repolymerization, cyclization and hydrogen-transfer reactions over Brønsted acid sites [4]. That was to say, high concentration of Brønsted acid sites contributed to a large amount of aromatics, which might lead to fast inactivation. Hydrogen-transfer reaction was present in the course of aromatization, which resulted in low selectivity of propylene, so the diminishment of Brønsted acid sites could explain the increase of propylene yield.

\section{Deactivation of 4.0 Mg-ZSM-5 zeolite catalyst}

A qualified catalyst needs not only high selectivity for main products, but also good performance in stability. In order to prepare such excellent catalyst, we chose 4.0 Mg-ZSM-5, which showed the best selectivity of propylene, to investigate the mechanism of deactivation of $\mathrm{Mg}$ modified zeolite catalyst.

The changes of acid type and acid distribution of fresh zeolite and zeolite after MTP reaction (denoted by $4.0 \mathrm{Mg}$ ZSM-5-AR) were showed in Fig. 6 and Table 4. Sample 4.0 Mg-ZSM-5-AR was obtained at $120 \mathrm{~min}$ of TOS. This experiment was carried out at $450{ }^{\circ} \mathrm{C}$ with a pure methanol feed at WHSV of $9.78 \mathrm{~h}^{-1}$ under atmospheric pressure.

From Fig. 6 and Table 4, it clearly shows that, at $120 \mathrm{~min}$ of TOS, the amount of total acid declined, especially that of strong acid. It could be inferred that, the reduction of total acid sites due to the coke covered on the active sites, prevented reactants from interacting with active sites. What's more, the coke mainly formed on strong acid sites, deduced from the substantial decline of strong acid sites.

Figure 7 shows the variation of different acid site quantity of 4.0 Mg-ZSM-5 zeolite catalyst before and after

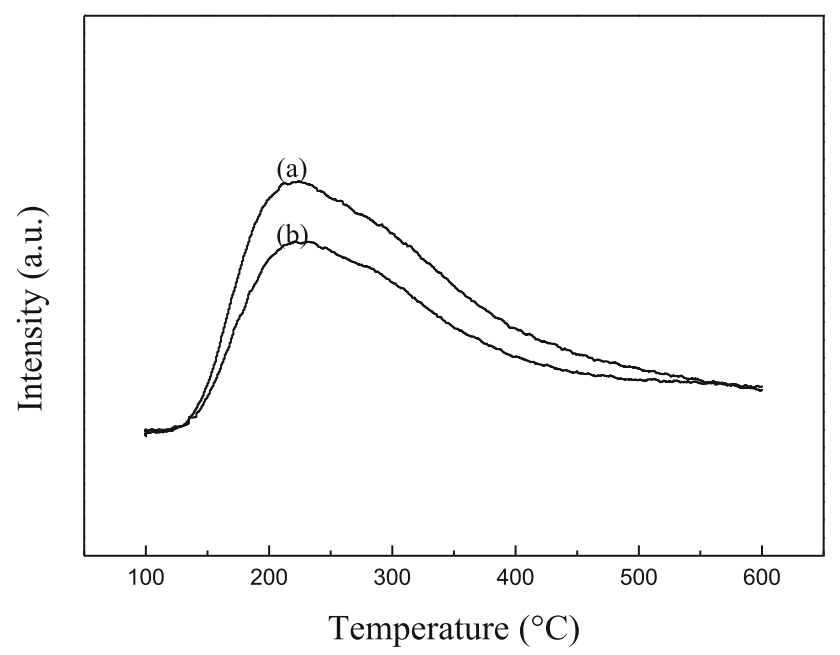

Fig. $6 \mathrm{NH}_{3}$-TPD plots of $4.0 \mathrm{Mg}-\mathrm{ZSM}-5$ zeolites ( $a$ fresh $4.0 \mathrm{Mg}$ ZSM-5 zeolite, $b 4.0 \mathrm{Mg}-\mathrm{ZSM}-5$ zeolite at $120 \mathrm{~min}$ of TOS)
Table 4 Acid properties of modified zeolites

\begin{tabular}{llll}
\hline Catalysts & $\begin{array}{l}\text { Weak acid } \\
\mathrm{mmol} / \mathrm{g}\end{array}$ & $\begin{array}{l}\text { Strong acid } \\
\mathrm{mmol} / \mathrm{g}\end{array}$ & $\begin{array}{l}\text { Total acid } \\
\mathrm{mmol} / \mathrm{g}\end{array}$ \\
\hline $4.0 \mathrm{Mg}-Z \mathrm{ZSM}-5$ & 0.316 & 1.155 & 1.471 \\
$4.0 \mathrm{Mg}-Z S M-5-A R$ & 0.241 & 0.788 & 1.029 \\
\hline
\end{tabular}

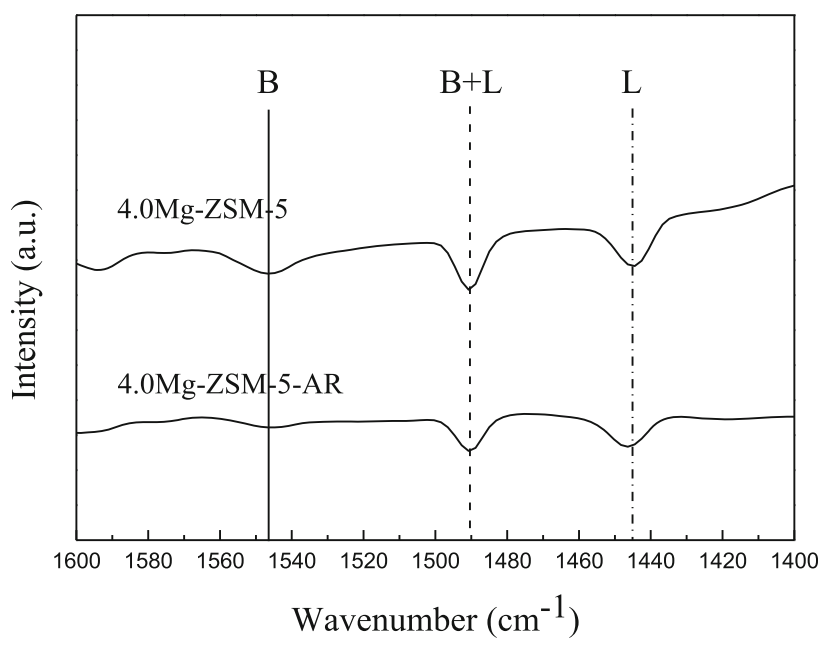

Fig. 7 Py-FTIR Spectra of 4.0 Mg-ZSM-5 zeolites

reaction. As can be seen in Fig. 7, the amount of Brønsted acid sites on 4.0 Mg-ZSM-5-AR diminished sharply compared with the fresh 4.0 Mg-ZSM-5, which indicated that strong Brønsted acid sites were the active site for coke formation. In order to extend the life time of catalyst, we need to reduce the amount of strong Brønsted acid sites and the strength of acid appropriately, on the premise of high conversion rate.

\section{Conclusion}

Magnesium modification of the H-ZSM-5 $\left(\mathrm{SiO}_{2} /\right.$ $\mathrm{Al}_{2} \mathrm{O}_{3}=38$ ) zeolite enhanced the MTP catalytic stability and raised the selectivity of propylene. For H-ZSM-5 $\left(\mathrm{SiO}_{2} / \mathrm{Al}_{2} \mathrm{O}_{3}=38\right)$, there was an optimal $\mathrm{Mg}$ loading content, 4.0 Mg-ZSM-5 showed the best catalytic stability and the highest propylene among magnesium modified zeolite catalysts. FT-IR data presented that nearly all Brønsted acid sites diminished over 8.0 Mg-ZSM-5 zeolite, the reduction of Brønsted acid degree was greater than that of Lewis acid. Therefore, it has been proposed that $\mathrm{Mg}$ interacted mainly with Brønsted acid sites. The diminishment of strong Brønsted acid sites explained the declination of ethylene and the increase of propylene in this experiment. Catalyst deactivated due to the coke generated during the reaction, coke formed mainly on strong 
Brønsted acid sites, the concentration of strong Brønsted acid sites influence the stability of catalyst.

Acknowledgments This work was financially supported by the project of National Natural Science Foundation of China (No. 21406270) and the project of Livelihood Program of Qingdao, China (No. 13-1-3-126-nsh).

Open Access This article is distributed under the terms of the Creative Commons Attribution 4.0 International License (http:// creativecommons.org/licenses/by/4.0/), which permits unrestricted use, distribution, and reproduction in any medium, provided you give appropriate credit to the original author(s) and the source, provide a link to the Creative Commons license, and indicate if changes were made.

\section{References}

1. Li J, Qi Y, Liu Zh, Liu G, Zhang D (2008) Co-reaction of Ethene and Methylation Agents over SAPO-34 and ZSM-22 [J]. Catal Lett 121:303

2. Chang CD, Kuo JCW, Lang Lang H et al (1978) Process studies on the conversion of methanol to gasoline [J]. Ind Eng Chem Process Design Dev 17(3):255-260

3. Sassi A, Wildman MA, Ahn HJ, Prasad P, Nicholas JB, Haw JF (2002) Methylbenzene chemistry on zeolite HBeta: multiple insights into methanol-to-olefin catalysis [J]. J Phys Chem B 106:2294

4. Dubois DR, Obrzut DL, Liu J et al (2003) Conversion of methanol to olefins over cobalt-, manganese-and nickel-incorporated SAPO-34 molecular sieves [J]. Fuel Process Technol 83(1):203-218

5. Schipper PH, Dwyer FG, Sparrell PT et al (1988) Zeolite ZSM-5 in fluid catalytic cracking: performance, benefits, and applications. In: Occelli ML (ed) Fluid catalytic cracking, ACS Symposium Series, vol 375, chap 5. American medical society, pp 64-86

6. Zhou F, Tian P, Liu Z et al (2007) Synthesis of ZSM-34 and its catalytic properties in methanol-to-olefins reaction $[\mathrm{J}]$. Chin $\mathrm{J}$ Catal 28(9):817-822

7. Miller LW (2000) Conversion of methanol to olefins where light olefins are desired products; non-zeolitic catalyst: U.S. Patent 6,166,282 [P]. 2000-12-26

8. Barger PT, Wilson ST, Holmgren JS (1992) Metal aluminophosphate catalyst for converting methanol to light olefins: U.S. Patent 5,126,308 [P]. 1992-6-30

9. Wilson S, Barger P (1999) The characteristics of SAPO-34 which influence the conversion of methanol to light olefins [J]. Microporous Mesoporous Mater 29(1):117-126

10. Yang Y, Sun C, Du J et al (2012) The synthesis of endurable B-Al-ZSM-5 catalysts with tunable acidity for methanol to propylene reaction [J]. Catal Commun 24:44-47
11. Xu A, Ma H, Zhang $\mathrm{H}$ et al (2013) Effect of boron on ZSM-5 catalyst for methanol to propylene conversion [J]. Polish J Chem Technol 15(4):95-101

12. Baig RBN, Varma RS (2013) Copper on chitosan: a recyclable heterogeneous catalyst for azide-alkyne cycloaddition reactions in water [J]. Green Chem 15(7):1839-1843

13. Liu J, Zhang C, Shen Z et al (2009) Methanol to propylene: effect of phosphorus on a high silica HZSM-5 catalyst [J]. Catal Commun 10(11):1506-1509

14. Inui $T$, Matsuda $H$, Yamase $O$ et al (1986) Highly selective synthesis of light olefins from methanol on a novel Fe-silicate [J]. Journal of Catalysis 98(2):491-501

15. Maxwell IE (1982) Nonacid catalysis with zeolites [J]. Adv Catal 31(2)

16. Arroyo PA, Souza-Aguiar EF, Monteiro JLF (1991) In: 202nd ACS National Meeting, vol 36, New York, Aug 1991

17. Kwak BS, Sachtler WMH (1994) Effect of Ga/proton balance in $\mathrm{Ga} / \mathrm{HZSM}-5$ catalysts on $\mathrm{C} 3$ conversion to aromatics [J]. J Catal 145(2):456-463

18. Ono Y (1992) Transformation of lower alkanes into aromatic hydrocarbons over ZSM-5 zeolites [J]. Catal Rev 34(3):179-226

19. Abramova AV (2010) Synthesis of ethylene and propylene on a SAPO-34 silica-alumina-phosphate catalyst [J]. Catal Ind 1:267-277

20. Zhao G, Teng J, Xie Z et al (2007) Effect of phosphorus on HZSM-5 catalyst for $\mathrm{C}$ 4-olefin cracking reactions to produce propylene [J]. J Catal 248(1):29-37

21. Zhuang J, Ma D, Yang G et al (2004) Solid-state MAS NMR studies on the hydrothermal stability of the zeolite catalysts for residual oil selective catalytic cracking [J]. J Catal 228(1):234-242

22. Othman I, Mohamed RM, Ibrahim IA et al (2006) Synthesis and modification of ZSM-5 with manganese and lanthanum and their effects on decolorization of indigo carmine dye [J]. Appl Catal A 299:95-102

23. Zhang S, Gong Y, Zhang L et al (2015) Hydrothermal treatment on ZSM-5 extrudates catalyst for methanol to propylene reaction: finely tuning the acidic property $[\mathrm{J}]$. Fuel Process Technol 129:130-138

24. Auroux A, Gervasini A (1990) Microcalorimetric study of the acidity and basicity of metal oxide surfaces [J]. J Phys Chem 94(16):6371-6379

25. Lee YJ, Kim JM, Bae JW et al (2009) Phosphorus induced hydrothermal stability and enhanced catalytic activity of ZSM-5 in methanol to DME conversion [J]. Fuel 88(10):1915-1921

26. Xue N, Chen X, Nie L et al (2007) Understanding the enhancement of catalytic performance for olefin cracking: hydrothermally stable acids in P/HZSM-5 [J]. J Catal 248(1):20-28

27. Hill IM, Al Hashimi S, Bhan A (2012) Kinetics and mechanism of olefin methylation reactions on zeolites [J]. J Catal 285(1):115-123

28. Zhu Q, Kondo JN, Setoyama T et al (2008) Activation of hydrocarbons on acidic zeolites: superior selectivity of methylation of ethene with methanol to propene on weakly acidic catalysts [J]. Chem Commun 41:5164-5166 